\title{
Phylogenetic analysis of Fasciola spp. isolated from slaughtered cattle in KwaZulu-Natal and Mpumalanga provinces of South Africa based on the cytochrome c oxidase subunit I mitochondrial marker
}

\begin{tabular}{|c|c|}
\hline \multicolumn{2}{|c|}{$\begin{array}{l}\text { Authors: } \\
\text { Tatenda J. Chikowore }{ }^{1} \text { (I) } \\
\text { Oliver T. Zishiri }{ }^{1} \text { (D) } \\
\text { Samson Mukaratirwa }{ }^{2} \text { (D) }\end{array}$} \\
\hline \multicolumn{2}{|c|}{$\begin{array}{l}\text { Affiliations: } \\
{ }^{1} \text { Discipline of Genetics, } \\
\text { School of Life Sciences, } \\
\text { College of Agriculture, } \\
\text { Engineering and Science, } \\
\text { University of KwaZulu-Natal, } \\
\text { Durban, South Africa }\end{array}$} \\
\hline \multicolumn{2}{|c|}{$\begin{array}{l}{ }^{2} \text { Discipline of Biological } \\
\text { Sciences, School of Life } \\
\text { Sciences, College of } \\
\text { Agriculture, Engineering } \\
\text { and Science, University of } \\
\text { KwaZulu-Natal, Durban, } \\
\text { South Africa }\end{array}$} \\
\hline \multicolumn{2}{|c|}{$\begin{array}{l}\text { Corresponding auth } \\
\text { Oliver Zishiri, } \\
\text { zishiri@ukzn.ac.za }\end{array}$} \\
\hline \multicolumn{2}{|c|}{$\begin{array}{l}\text { Dates: } \\
\text { Received: } 09 \text { Oct. } 2018 \\
\text { Accepted: } 12 \text { Feb. } 2019 \\
\text { Published: } 18 \text { June } 2019\end{array}$} \\
\hline \multicolumn{2}{|c|}{$\begin{array}{l}\text { How to cite this article: } \\
\text { Chikowore, T.J., Zishiri, O.T. \& } \\
\text { Mukaratirwa, S., 2019, } \\
\text { 'Phylogenetic analysis } \\
\text { of Fasciola spp. isolated } \\
\text { from slaughtered cattle } \\
\text { in KwaZulu-Natal and } \\
\text { Mpumalanga provinces of } \\
\text { South Africa based on the } \\
\text { cytochrome c oxidase subunit } \\
\text { I mitochondrial marker', } \\
\text { Onderstepoort Journal of } \\
\text { Veterinary Research } 86(1), \\
\text { a1706. https://doi.org/ } \\
\text { 10.4102/ojvr.v86i1.1706 }\end{array}$} \\
\hline \multicolumn{2}{|l|}{ Read online: } \\
\hline 回龂回 & $\begin{array}{l}\text { Scan this QR } \\
\text { code with your } \\
\text { smart phone or } \\
\text { mobile device } \\
\text { to read online. }\end{array}$ \\
\hline
\end{tabular}

Fasciola spp. are the causative agents of fascioliasis in humans and livestock. Before the development of control and management measures, the geographical distribution of the species and patterns of infection must be considered. Because of difficulties in the phenotypic differentiation and morphometric classification of Fasciola spp., DNA molecular markers have become more useful for fluke differentiation and description of phylogenetic patterns. This study aimed to differentiate and describe the phylogenetic background of Fasciola spp. isolated from cattle slaughtered at three abattoirs in the Mpumalanga and KwaZulu-Natal provinces of South Africa. The cytochrome c oxidase I (COI) - FHCO1 (forward: 5'-TTGG TTTTTTGGGCATCCT-3') and FHCO1 (reverse: 5' -AGGCCACCACCAAATAAAAGA3') - marker was sequenced from 55 Fasciola flukes that were collected from abattoirs in catchment areas of the KwaZulu-Natal and Mpumalanga provinces. Fasciola hepatica was demonstrated to have $100 \%$ prevalence in KwaZulu-Natal and Mpumalanga (highveld), respectively, and 76\% prevalence in the lowveld (Belfast area) of Mpumalanga. Two animals from the Belfast metapopulation were co-infected with both Fasciola gigantica and F. hepatica. DNA sequence analysis of all the isolates demonstrated a sequence conservation of 0.472 , nucleotide diversity of 0.082 and Tajima's D of -1.100 ; however, it was not statistically significant $(p>0.05)$. Twentytwo haplotypes were identified, with 18 novel haplotypes being unique to the isolates from South Africa. Within the study samples, 12 haplotypes were isolated to a few individuals, with a haplotype diversity of 0.8957 indicating high genetic diversity. Principal coordinate analysis supported the clustering and distribution of the haplotypes, with $11.38 \%$ of the variation being attributed to coordinate 2 and 55.52\% to coordinate 1. The distribution of Fasciola spp. has been demonstrated to be related to the distribution of the freshwater intermediate host snails, Lymnaea spp., as well as the relative altitude of the localities in South Africa. Information provided by this study serves as preliminary evidence for further studies on the mapping of the distribution of F. gigantica and F. hepatica in South Africa, which is key in designing control programmes for fascioliasis in humans and livestock.

Keywords: mtDNA; haplotype; phylogeny; interspecific; metapopulation; lymnaea.

\section{Introduction}

Fascioliasis is a food-borne parasitic disease with a near global distribution and dire socioeconomic effects because of human and livestock mortalities, retarded growth, reduced meat and milk production, condemnation of infected livers, animal emaciation and cost of anthelmintics for treatment (Mas-Coma et al. 2004; Mas-Coma, Valero \& Bargues 2009b; Spithill \& Dalton 1998). The disease occurs as a result of infection by digenean trematode species of the genus Fasciola. Several species have been described under the genus, with the taxonomic standing still under scrutiny and debate (Agatsuma et al. 2000; Ai et al. 2011; Hashimoto et al. 1997; Itagaki et al. 1998). However, the main causative agents of fascioliasis in livestock and humans are Fasciola hepatica and Fasciola gigantica, with hybrids being reported in areas where the distribution of the two species overlap (Ai et al. 2011; Ashrafi 2015; Walker et al. 2008; WHO 1995). Studies have reported the presence of F. hepatica in Africa, America, Asia, Europe and tropical islands of the Pacific (Mas-Coma, Bargues \& Valero 2005; Mas-Coma et al. 2009b; Mucheka et al. 2015; Nguyen et al. 2009; Walker et al. 2008). Fasciola gigantica, on the contrary, has a limited geographical distribution and has been reported in Africa and Asia and some parts of southern Europe (Mas-Coma \& Bargues 1997). The two

Copyright: @ 2019. The Authors. Licensee: AOSIS. This work is licensed under the Creative Commons Attribution License. 
trematode species are known to mainly infect humans and ruminant animals, resulting in losses in livestock production, fertility and resistance to draught in ruminants (Bernardo et al. 2011; Keiser \& Utzinger 2007). Economic losses in livestock have been reported to exceed $\$ 3$ billion annually, with the zoonotic aspect of the disease also making it a public health concern (Mas-Coma et al. 2009a; Spithill \& Dalton 1998).

Fasciola hepatica and F. gigantica exhibit similar life cycles (Graczyk \& Fried 1999; Mas-Coma \& Bargues 1997). The diheteroxenous life cycle of Fasciola (Andrews 1999) is dependent on Lymnaeid freshwater snails as the intermediate hosts for both F. hepatica and F. gigantica (Bargues et al. 2001). Lymnaeids have been reported to act as intermediate hosts to numerous other trematode species depending on the geographical region, ecology and snail-parasite specificity (Bargues et al. 2001; De Kock, Wolmarans \& Bornman 2003; Mas-Coma et al. 2005). The life cycle of Fasciola includes an intermediate host snail and a definitive host with complex reproductive biology, which results in high gene flow and genetic variability within Fasciola spp. populations (Cwiklinski et al. 2015). Studies have shown that multiple Lymnaeid snail species may be susceptible to Fasciola (De Kock, Joubert \& Pretorius 1989; Mas-Coma et al. 2009) and this may also contribute to potential population sub-structuring as well as development of distinct genetic clusters between different geographical localities (Beesley et al. 2017; Vilas, Vázquez-Prieto \& Paniagua 2012).

Over the last few decades, reports of fascioliasis have increased, resulting in the increasing need for taxonomic clarity as well as differentiation of the two fasciolid species. Fasciola gigantica and F. hepatica overlap in their geographical distribution (Mucheka et al. 2015; Robles-Pérez et al. 2015), and this has resulted in numerous discussions and notions on the taxonomic patterns and identity of Fasciola spp. as well as observed intermediate forms (Agatsuma et al. 2000; Ai et al. 2011; Itagaki et al. 1998; Itagaki \& Tsutsumi 1998; Nguyen et al. 2009; Periago et al. 2007). Morphological techniques, primarily used in diagnosis, take their basis on the differentiation of morphological characteristics of eggs and the adult fluke (Cuomo, Noel \& White 2009; Mas-Coma et al. 2005; Thanh 2012). However, these techniques have limited sensitivity and specificity as they require skilled taxonomists who are scarcely available in many parts of the world such as South Africa. There have also been several reports of hybrids of F. gigantica and F. hepatica, which may not be morphologically differentiated from the main species (Itagaki \& Tsutsumi 1998; Itagaki et al. 1998; Schweizer et al. 2007). With the increase in reports of fascioliasis and the rapid emergence of resistance to anthelmintics, further genetic analysis studies are therefore warranted. Resistance to triclabendazole to the recommended treatment dose has been reported from several parts of Eurasia (Brennan et al. 2007; Brockwell et al. 2014; Fairweather 2009; Kelley et al. 2016; Peng et al. 2009; Vilas et al. 2012), with a report of potential resistance of F. hepatica to treatment in a human case in the Netherlands (Winkelhagen et al. 2012).
Treatment and control of fascioliasis largely depends on early diagnosis of infection, and with advances in DNA technology, application of molecular markers for species identification and genetic characterisation has become necessary in studying Fasciola isolates (Cwiklinski et al. 2015; Elliott et al. 2014; Mucheka et al. 2015;).

Studies have shown the utility of nuclear ribosomal markers such as ITS 1 and ITS 2 in species identification; however, mitochondrial markers are highly variable and can resolve taxonomic patterns of more closely related species and/or populations (Mucheka et al. 2015; Patwardhan, Ray \& Roy 2014). The cytochrome c oxidase subunit I (COI) and nicotin adenin dinucleotide dehydrogenase (NADH dehydrogenase) subunit I (NadI) have been used as molecular markers for elucidating the phylogenetic relationships of Fasciola spp. and describing to an extent the genetic diversity of Fasciola populations (Ai et al. 2011; Hashimoto et al. 1997; Itagaki et al. 1998; Mucheka et al. 2015; Peng et al. 2009; Semyenova et al. 2006). The COI marker is widely regarded as an efficient DNA barcode and has been commonly used in species identification and differentiation of Fasciola spp. in recent studies in South Africa and Zimbabwe (Mucheka et al. 2015).

Against this background, the present study was aimed at identifying Fasciola spp. isolates collected from cattle slaughtered at abattoirs located in KwaZulu-Natal (KZN) and Mpumalanga (MP) provinces using the (mtDNA) COI region and also examining interspecies genetic diversity among the isolates using COI haplotypes.

\section{Materials and methods Study areas and collection of samples}

A total of 55 flukes were collected from cattle at three abattoirs located in the KZN and MP provinces (Figure 1), respectively. The abattoirs served as catchment areas for cattle slaughtered in their respective areas and the exact location of origin of each animal was not determined. Twenty-one flukes were collected from cattle originating from the Swartberg and Lions River in the Underberg area of KZN (one fluke was collected from each animal), 17 were collected from the Barberton abattoir, Belfast, MP (two to three flukes collected per animal) and 17 from the Mpumalanga highveld, MP (one fluke from each animal) (Table 1).

The Underberg region of KZN has a warm and cold season, with an average temperature of $14.1^{\circ} \mathrm{C}$. The average annual rainfal is $985 \mathrm{~mm}$, with the altitude being $1540 \mathrm{~m}$ above sea level (Climate-Data 2017a). The climate and weather patterns in the Mpumalanga province depend on the topography of the specific region analysed. In Belfast, which is in the lowveld, the climate is warm and temperate and the average temperature is $13.2{ }^{\circ} \mathrm{C}$ and the average annual precipitation is $835 \mathrm{~mm}$. In the highveld, the average annual temperature is $15.5^{\circ} \mathrm{C}$, with rainfall averaging $683 \mathrm{~mm}$. The altitude of the province ranges from $1500 \mathrm{~m}$ to more than $2000 \mathrm{~m}$ above sea level. A decrease in temperature is noted from east to west, with the increase in altitude (Climate-Data 2017b). 


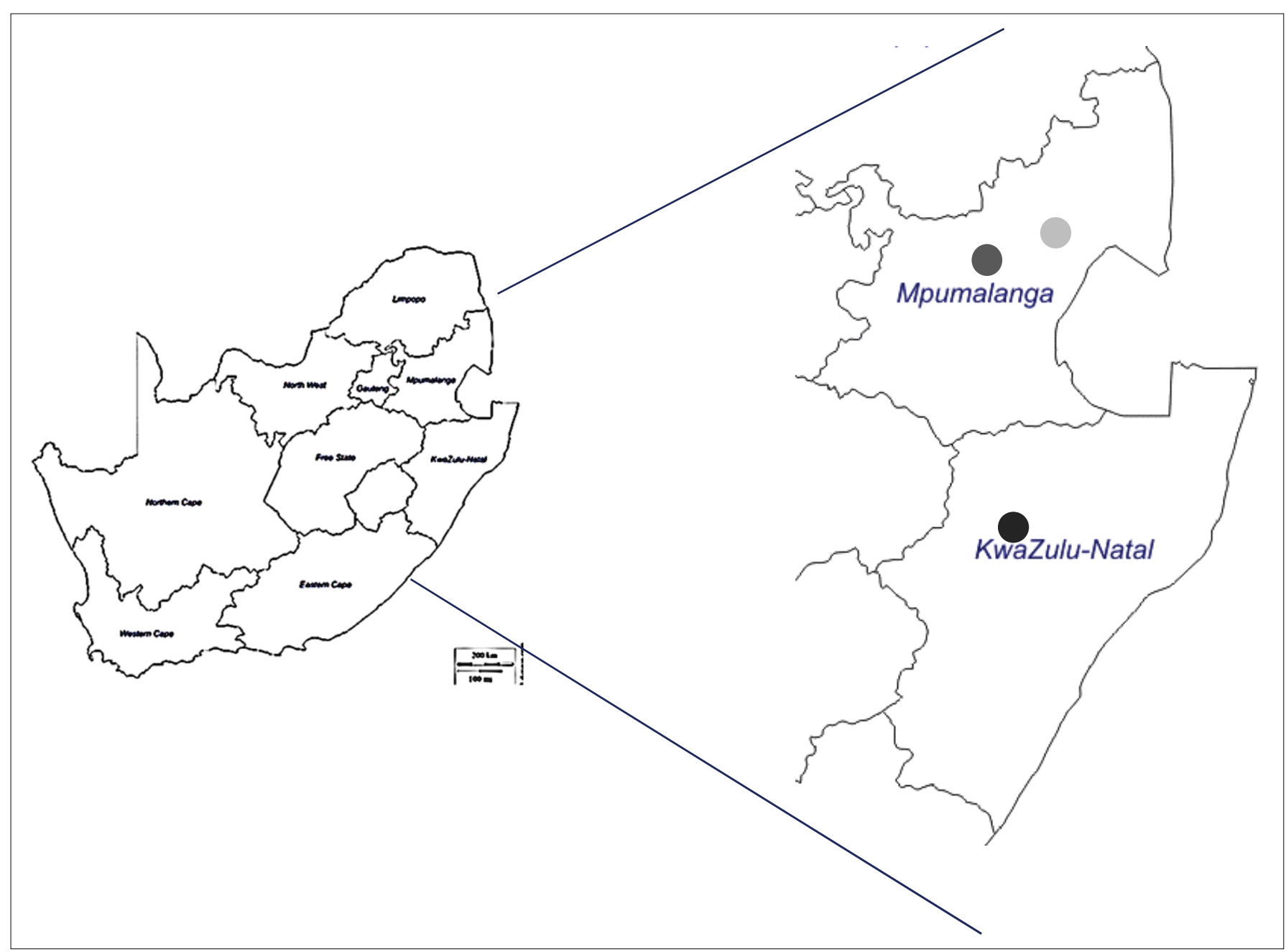

FIGURE 1: Localities were Fasciola spp. isolates were collected for the study. Black, Underberg (KwaZulu-Natal); grey, highveld Mpumalanga; light grey, Barberton abattoir.

TABLE 1: Identity of Fasciola spp. isolates from three locations in KwaZulu-Natal and Mpumalanga provinces of South Africa based on COI mitochodrial marker sequences.

\begin{tabular}{|c|c|c|c|c|c|c|}
\hline \multirow[t]{2}{*}{ Province } & \multirow[t]{2}{*}{ Origin of cattle } & \multirow[t]{2}{*}{ Number of isolates } & \multicolumn{2}{|c|}{ Identity of isolates } & \multirow{2}{*}{$\begin{array}{l}\% \text { Prevalence } \\
\text { of } F \text {. hepatica }\end{array}$} & \multirow{2}{*}{$\begin{array}{l}\text { No. of cattle with } \\
\text { co- infection }\end{array}$} \\
\hline & & & F. hepatica & F. gigantica & & \\
\hline KwaZulu-Natal & Underberg & 21 & 21 & 0 & 100 & 0 \\
\hline Mpumalanga & Highveld & 17 & 17 & 0 & 100 & 0 \\
\hline Mpumalanga & Lowveld (Paardeplaas, Belfast) & 17 & 13 & 4 & 76 & 2 \\
\hline
\end{tabular}

\section{DNA extraction, amplification and sequencing}

The genomic DNA was isolated from tissue from the posterior end of the fluke using the phenol-chloroform method, which uses sodium dodecylsulfate (SDS) and proteinase $\mathrm{K}$ to enzymatically digest proteins and non-nucleic acid cellular components. A mixture of phenol:chloroform:isoamyl alcohol (25:24:1) was used to separate lipids and cellular debris into the organic phase, resulting in isolated DNA being in the aqueous phase (McKiernan \& Danielson 2017). All DNA was stored at $-20{ }^{\circ} \mathrm{C}$ until further analysis. Polymerase chain reaction (PCR) amplification of the partial COI region was done using the primers FHCO1 (forward: 5'-TTGGTTTTTTGGGCATCCT-3') and FHCO1 (reverse: 5' -AGGCCACCACCAAATAAAAGA3') (Mucheka et al. 2015).

All PCR reactions were performed in $25 \mu \mathrm{L}$ volumes, with each reaction containing $12.5 \mu \mathrm{L}$ of DreamTaq PCR Master Mix (2X), $0.5 \mu \mathrm{L}$ per primer of the forward and reverse primers, $10.5 \mu \mathrm{L}$ of nuclease free water and $1 \mu \mathrm{L}$ of template DNA. PCR was performed using a thermocycler (Bio-Rad, Hercules, CA, United States) under the following cycling conditions: initial denaturation at $95^{\circ} \mathrm{C}$ for 3 minutes (min), followed by 48 cycles of denaturation at $95^{\circ} \mathrm{C}$ for 30 seconds (s), annealing at $59^{\circ} \mathrm{C}$ for $30 \mathrm{~s}$ and $72{ }^{\circ} \mathrm{C}$ for $1 \mathrm{~min}$ and a final elongation step of $10 \mathrm{~min}$ at $72{ }^{\circ} \mathrm{C}$, with a $10^{\circ} \mathrm{C}$ hold.

Polymerase chain reaction products were run on a $1 \%(\mathrm{w} / \mathrm{v})$ agarose gel, which was stained with ethidium bromide. On each gel, a molecular weight marker of 100-1000 base pairs (bp) (O'GeneRuler, Fermentas, South Africa) was used to determine the size of visible bands. The gel was viewed using the ChemiDoc ${ }^{\mathrm{TM}}$ MP Imaging System (Bio-Rad) to confirm amplification.

The unpurified PCR products were subsequently sent to the Central Analytical Facilities (CAF), Stellenbosch University 
(South Africa) for sequencing in the forward direction using next-generation Sanger sequencing technology. Using this technology, PCR-amplified DNA was denatured to single strands and chain-terminating dideoxynucleotides (ddNTPs) were added to the reaction. During DNA replication, the chain-terminating ddNTPs were selectively hybridized to the template strand by DNA polymerase. The chain-terminating signals were then used to determine the identity of the bases (Jamuar, D'Gama \& Walsh 2016).

\section{Sequence analysis}

BioEdit version 7.2.5 (Hall 2013) was used to edit all sequences by calling up the base peaks in the chromatogram and adjusting $\mathrm{N}, \mathrm{S}$ and $\mathrm{K}$ substitutions to appropriate the nucleotide bases. Sequence identity was then confirmed (Table 4) using the nucleotide Basic Local Alignment Search Tool (BLAST) in the National Centre for Biotechnology (NCBI; www.ncbi.nlm.nih.gov/). Sequence alignment was performed using the MUltiple Sequence Comparison by Log-Expectation (MUSCLE) function in Mega 7, with the ends of the sequences being trimmed. The DNA Sequence Polymorphism (DnaSP) version 5 software (Librado \& Rozas 2009) was used to estimate the sequence conservation, nucleotide diversity, haplotype diversity and population neutrality (Tajima's D). Data were formatted as haploid mitochondrial DNA sequences, with nucleotide diversity being calculated using gaps or missing data considered. PAST version 3.19 (Hammer, Harper \& Ryan 2001) and principal coordinate analysis (PCoA) were used for multivariate ordination analysis. The PCoA plot was generated using the Gower similarity index and $c=2$ transformation exponent. Phylogenetic relationships among the populations were inferred using MrBayes version 3.2.6 (Ronquist \& Huelsenbeck 2003). Four Markov chains were run for 200000 generations to ensure a standard deviation of split frequencies less than 0.01 . The print frequency was set to 1000, with a sample frequency of 10 and a burn-in period of 20000 for Bayesian inference (BI). The haplotype network was constructed using Network 5 (Bandelt, Forster \& Röhl 1999) and the median joining rooting method under default (10) weight and with epsilon $(\varepsilon)$ set to 0 .

\section{Ethical considerations}

This study was approved by the Animal Research Ethics Committee of the University of KwaZulu-Natal (AREC/044/016PD).

\section{Results}

\section{Fluke identification}

The trimmed COI sequences were BLAST searched against the NCBI GenBank database to obtain the closest matches, with percentage identities (Table 4) observed averaging 95\% over the lowest expected values. Based on the COI sequence identities, all isolates from the Underberg region of KZN were identified as F. hepatica, with a prevalence of $100 \%$
$(21 / 21)$, and the same results were observed with the isolates from the MP highveld (17/17). Thirteen isolates were identified as F. hepatica $(76 \% ; 13 / 17)$ and four isolates as F. gigantica (24\%; 4/17) from the Barberton abattoir in the Belfast area of MP (Figure 2). Two animals were co-infected with both F. hepatica and F. gigantica (Table 1).

\section{Sequence variation and diversity}

The aligned KZN sequences showed a sequence conservation of 0.57 , indicating moderate sequence variation although conservation was high (Table 2). The nucleotide diversity was estimated to be 0.086 , indicating a low probability of difference in random sequences. Tajima's test was performed to examine the deviation of the sequences from mutation drift equilibrium. The test yielded a Tajima's D statistic of -0.75339 , which is indicative of negative selection; however, the results were not statistically significant $(p>0.10)$. The Belfast (MP) sequences showed a sequence conservation of 0.641 , indicating high sequence conservation (Table 2). The nucleotide diversity was estimated to be 0.069 , also indicating low probability of random sequence difference. Tajima's test showed a D value of -0.84641 ; however, it was not statistically significant $(p>0.10)$. Highveld (MP) sequences showed a sequence conservation of 0.457 , indicating a higher sequence variation than conservation. The nucleotide diversity was estimated to be 0.109 . A Tajima's D of -0.608 is also indicative of negative selection although not significant $(p>0.10)$ (Table 2).

The total aligned sequences showed a sequence conservation of 0.472 , indicating moderate sequence variation with higher variable sites than conserved sites. The nucleotide diversity was estimated to be 0.082 , showing low probability of random sequence difference. Tajima's D was estimated to be -1.100 and not statistically significant $(p>0.05)$ (Table 2). The lack of significance in Tajima's D could be attributed to the small sample size or could indicate the neutrality of the population.

\section{Genetic distances between haplotypes}

The genetic $p$-distances between the F. hepatica isolates ranged from 0.01 to 0.28 , while a range of $0.02-0.04$ was observed for the F. gigantica isolates. Interestingly, the Highveld haplotypes (H_15, H_16, H_17, H_20) showed a relatively higher genetic distance to the rest of the $F$. hepatica haplotypes, with a range from 0.09 to 0.28 (Table 3). Genetic distance between haplotypes identified within the two study species ranged from 0.07 to 0.35 (Table 3), indicating a close relation between isolates of the same species and a relatively distant interspecies genetic relation.

\section{Phylogenetic analysis}

The phylogenetic analysis based on the COI gene showed two main clades as shown in Figure 3. The first clade constitutes F. hepatica based on the identity of sequences (Table 4) from GenBank and the current study samples, which were well 


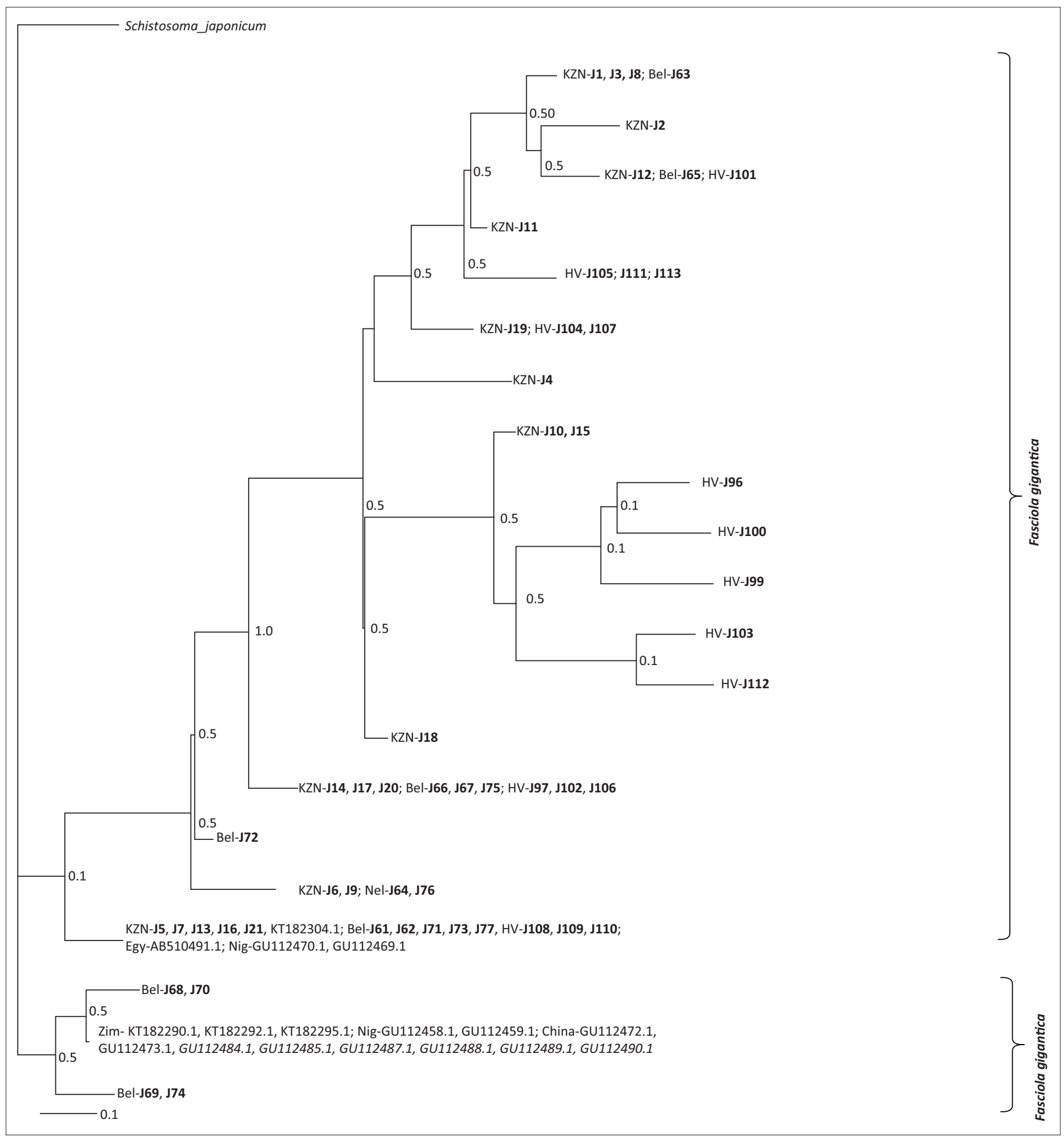

FIGURE 2: Phylogram based on haplotypes from COI sequences of Fasciola spp. populations from South Africa (KwaZulu-Natal and Mpumalanga provinces) and GenGank sequences using Bayesian inference. Experimental isolates are highlighted in bold and Fasciola spp. intermediates are shown in italics.

TABLE 2: Sequence diversity of COI in Fasciola isolates from the Kwa-Zulu Natal and Mpumalanga provinces.

\begin{tabular}{|c|c|c|c|c|c|}
\hline Population & Number of haplotypes & Haplotype diversity (hd) & Nucleotide diversity $(\pi)$ & Tajima's D & Sequence conservation \\
\hline Kwa-Zulu Natal & 13 & 0.8880 & 0.08632 & -0.75339 & 0.573 \\
\hline Mpumalanga (Highveld) & 9 & 0.7328 & 0.10911 & -0.60777 & 0.457 \\
\hline Mpumalanga Lowveld (Belfast) & 6 & 0.7378 & 0.06901 & -0.84641 & 0.641 \\
\hline Combined & 22 & 0.8957 & 0.08249 & -1.10025 & 0.472 \\
\hline
\end{tabular}

supported. The clade contained F. hepatica samples from all study sites and GenBank sequences from Egypt, Niger and South Africa (Pietermaritzburg). The second clade constitutes
F. gigantica based on GenBank samples from Zimbabwe, Niger and China (including intermediates) and sequences from Belfast in our current study. 
TABLE 3: Estimates of genetic distances between haplotypes based on $\mathrm{COI}$ sequences of experimental and GenBank Fasciola spp. isolates.

\begin{tabular}{|c|c|c|c|c|c|c|c|c|c|c|c|c|c|c|c|c|c|c|c|c|c|c|}
\hline . & 11 & 2 & -3 & 14 & 1_5 & H_6 & 7 & 8 & 9 & 0 & 1 & H_14 & 5 & 6 & 7 & 8 & 9 & 0 & 2 & 3 & 1 & H_22 \\
\hline & 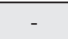 & & & & & & & & & & & & & & & & & & & & & \\
\hline & .04 & & & & & & & & & & & & & & & & & & & & & \\
\hline & & & 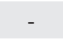 & & & & & & & & & & & & & & & & & & & \\
\hline & & & & - & & & & & & & & & & & & & & & & & & \\
\hline & & & & & - & & & & & & & & & & & & & & & & & \\
\hline & & & & & & 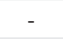 & & & & & & & & & & 0.02 & & & & & & \\
\hline & & & & & & & 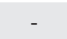 & & & & & & & & & .02 & & & & & & o \\
\hline & & & & & & & 05- & - & & & & & & & & 0.02 & & & 2 & & & 0.05 \\
\hline & & & & & & & & & 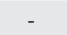 & & 0.01 & & & & & & & & & & & 05 \\
\hline & & & & & & & & & & - & & & & & & & & & & & & \\
\hline & . & . & & 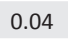 & 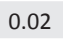 & 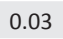 & 66 & 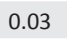 & 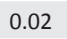 & - & & me & . & 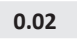 & 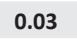 & - & - & 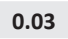 & - & .02 & 2 & 0.05 \\
\hline & 03 & & 10 & 2 & 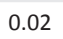 & 02 & 05 & 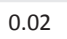 & .01 & 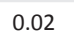 & 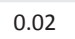 & & (2) & 0.0 & 0.03 & 0.02 & 0.01 & 0.03 & 0.02 & .02 & 2 & 0.05 \\
\hline & & & & & & 26 & & 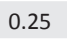 & דר & & 20 & & & 0.03 & 0.03 & 0.04 & 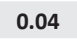 & or & 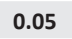 & .05 & & 0.12 \\
\hline & & & & & & & & & .11 & & & & 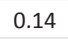 & 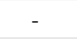 & 0.02 & 0.02 & 0.02 & 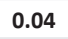 & .03 & 3 & & 0.07 \\
\hline & 1 & & & & & & & & .18 & & , & 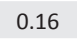 & 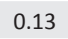 & .12 & 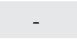 & 0 & 00 & 4 & 4 & 4 & 4 & 0.09 \\
\hline 10 & .06 & 05 & ר. & 0 & 05 & 05 & 07 & 05 & 05 & 0.05 & 006 & 0.05 & 2 & 0 & 0.14 & 0.08 & 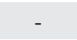 & .03 & .02 & .02 & .02 & .05 \\
\hline & & & & & & & & & & & & & & & & & & - & & & & 08 \\
\hline & & & & & & & & & & & & & & & & & & & 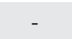 & 1 & 0 & .04 \\
\hline & 12 & 09 & & & & & & & 0.09 & & & & & & & & & & 0.02 & & 0.01 & 0.05 \\
\hline & & & & & & & & & & & & & & 0. & & & & & 2 & 14 & - & 0.04 \\
\hline 2 & 35 & 31 & 39 & 30 & 32 & 33 & 36 & 33 & .31 & .32 & 0.33 & .33 & .62 & .44 & 0.51 & 0.44 & 0.36 & 0.51 & 0.28 & .31 & 0.27 & - \\
\hline
\end{tabular}

Note: Genetic p-distances are shown below the diagonal and the standard error(s) (bold) are shown above the diagonal.

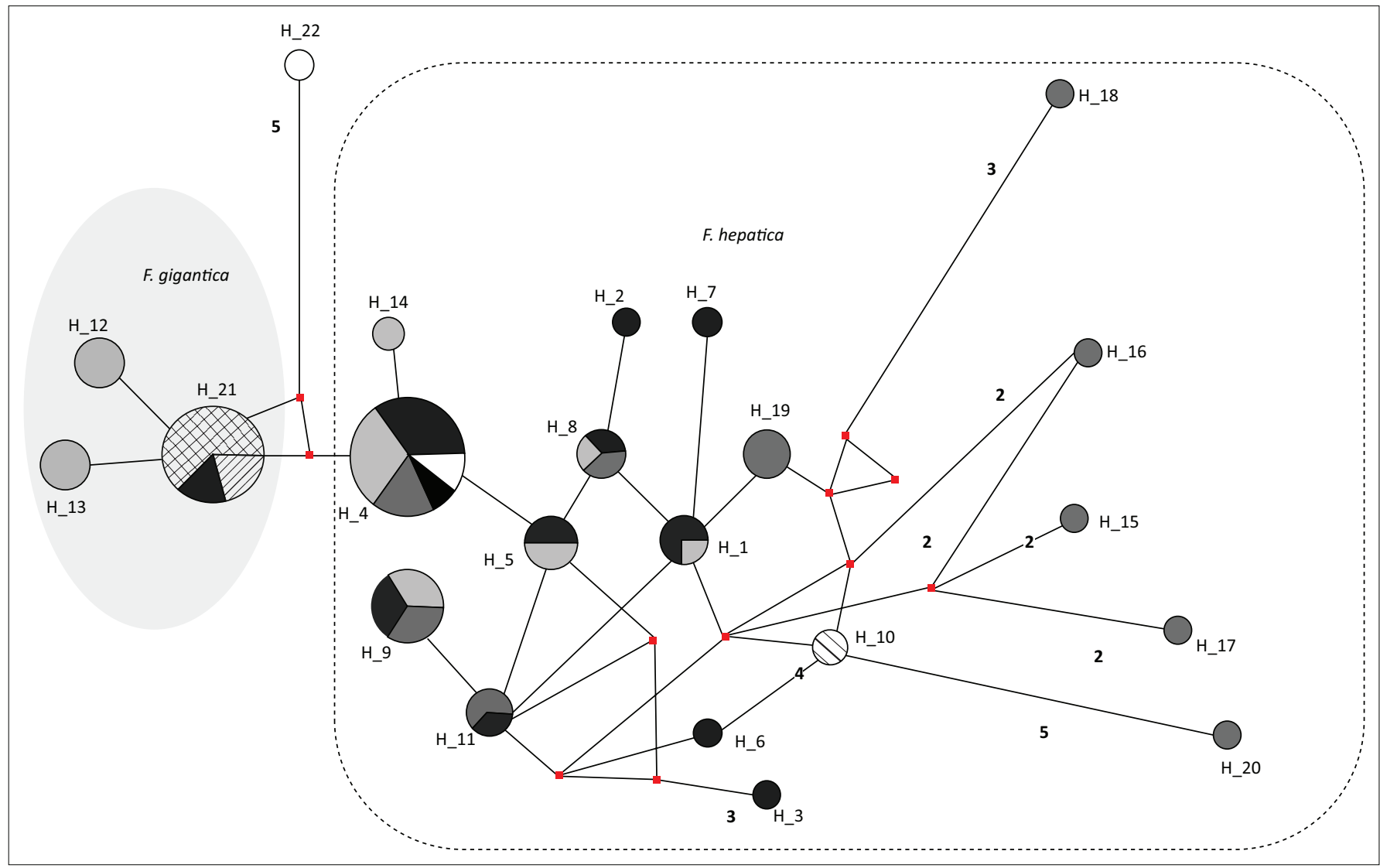

FIGURE 3: Haplotype network of Fasciola spp. isolates from the study and GenBank sequences. Haplotypes are represented by circles with the size of the circle indicating the number of sequences sharing that haplotype. The red squares represent median vectors. Numbers adjacent to haplotype links are the number of inferred mutational steps if more than one. Each colour is representative of the relevant geographical locality of the samples. Black fill, Niger; dark grey fill, Underberg (KwaZulu-Natal, South Africa); grey, Highveld (Mpumalanga, South Africa); light grey, Belfast (Mpumalanga, South Africa); white, Egypt; backward diagonal, Zimbabwe; diagonal cross, China; bold circle, outgroup.

\section{Haplotype distribution}

Analysis of experimental and GenBank Fasciola spp. sequences showed 22 haplotypes, with a relatively high diversity of 0.896 . Haplotype H_4 was shared by F. hepatica sequences from KZN, Belfast, Highveld Mpumalanga, Niger and China (Figure 4). Haplotype H_21 was shown to include F. gigantica sequences from China, Niger and Zimbabwe and notably did not include any of the F. gigantica study 
TABLE 4: Identity and locality of Fasciola spp. used in this study and including GenBank sequences.

\begin{tabular}{|c|c|c|c|c|}
\hline Sample & Locality & Identity & $\%$ Identity & Haplotype \\
\hline J1 & \multirow{21}{*}{$\begin{array}{l}\text { KwaZulu-Natal } \\
\text { (KZN) }\end{array}$} & F. hepatica & 91 & H_1 \\
\hline $\mathrm{J} 2$ & & F. hepatica & 95 & $\mathrm{H} \_2$ \\
\hline J3 & & F. hepatica & 95 & H_1 \\
\hline J4 & & F. hepatica & 98 & H_3 \\
\hline J5 & & F. hepatica & 98 & $\mathrm{H}_{-} 4$ \\
\hline J6 & & F. hepatica & 93 & H_5 \\
\hline J7 & & F. hepatica & 95 & $H_{-} 4$ \\
\hline 18 & & F. hepatica & 92 & H_1 \\
\hline J9 & & F. hepatica & 93 & H_5 \\
\hline J10 & & F. hepatica & 93 & H_6 \\
\hline J11 & & F. hepatica & 91 & $\mathrm{H}_{-} 7$ \\
\hline J12 & & F. hepatica & 95 & H_8 \\
\hline J13 & & F. hepatica & 97 & $\mathrm{H}_{-} 4$ \\
\hline J14 & & F. hepatica & 97 & H_9 \\
\hline J15 & & F. hepatica & 94 & H_6 \\
\hline J16 & & F. hepatica & 99 & $\mathrm{H}_{-} 4$ \\
\hline J17 & & F. hepatica & 95 & H_9 \\
\hline J18 & & F. hepatica & 94 & H_10 \\
\hline J19 & & F. hepatica & 93 & H_11 \\
\hline $\mathrm{J} 20$ & & F. hepatica & 98 & H_9 \\
\hline $\mathrm{J} 21$ & & F. hepatica & 99 & H_4 \\
\hline J61 & \multirow[t]{17}{*}{ Belfast } & F. hepatica & 99 & $\mathrm{H} \_4$ \\
\hline J62 & & F. hepatica & 96 & $\mathrm{H}_{-} 4$ \\
\hline J63 & & F. hepatica & 91 & H_1 \\
\hline$J 64$ & & F. hepatica & 96 & H_5 \\
\hline$J 65$ & & F. hepatica & 90 & $\mathrm{H} \_8$ \\
\hline J66 & & F. hepatica & 98 & H_9 \\
\hline$J 67$ & & F. hepatica & 97 & H_9 \\
\hline J68 & & F. gigantica & 99 & H_12 \\
\hline J69 & & F. gigantica & 96 & H_13 \\
\hline J70 & & F. gigantica & 99 & H_12 \\
\hline J71 & & F. hepatica & 97 & $\mathrm{H}_{-} 4$ \\
\hline $\mathrm{J} 72$ & & F. hepatica & 95 & H_14 \\
\hline J73 & & F. hepatica & 100 & H_4 \\
\hline$J 74$ & & F. gigantica & 96 & H_13 \\
\hline $\mathrm{J} 75$ & & F. hepatica & 97 & H_9 \\
\hline J76 & & F. hepatica & 95 & H_5 \\
\hline J77 & & F. hepatica & 99 & H_4 \\
\hline J96 & \multirow{17}{*}{$\begin{array}{l}\text { Mpumalanga } \\
\text { Highveld }\end{array}$} & F. hepatica & 84 & H_15 \\
\hline J97 & & F. hepatica & 96 & H_9 \\
\hline J99 & & F. hepatica & 89 & H_16 \\
\hline J100 & & F. hepatica & 91 & H_17 \\
\hline J101 & & F. hepatica & 96 & H_8 \\
\hline J102 & & F. hepatica & 97 & H_9 \\
\hline J103 & & F. hepatica & 93 & H_18 \\
\hline J104 & & F. hepatica & 93 & H_11 \\
\hline J105 & & F. hepatica & 92 & H_19 \\
\hline J106 & & F. hepatica & 96 & H_9 \\
\hline J107 & & F. hepatica & 92 & H_11 \\
\hline J108 & & F. hepatica & 99 & H_4 \\
\hline J109 & & F. hepatica & 99 & H_4 \\
\hline J110 & & F. hepatica & 97 & H_4 \\
\hline J111 & & F. hepatica & 93 & H_19 \\
\hline J112 & & F. hepatica & 90 & H_20 \\
\hline J113 & & F. hepatica & 92 & H_19 \\
\hline KT182290.1 & \multirow[t]{3}{*}{ Zimbabwe (Zim) } & F. gigantica & $N / A$ & H_21 \\
\hline KT182292.1 & & F. gigantica & $N / A$ & H_21 \\
\hline KT182295.1 & & F. gigantica & $N / A$ & H_21 \\
\hline AB510491.1 & Egypt & F. hepatica & $N / A$ & H_4 \\
\hline KT182304.1 & PMB (KZN) & F. hepatica & $N / A$ & H_4 \\
\hline
\end{tabular}

TABLE 4 (Continues...): Identity and locality of Fasciola spp. used in this study and including GenBank sequences.

\begin{tabular}{lllcc}
\hline Sample & Locality & Identity & \% Identity & Haplotype \\
\hline GU112458.1 & Niger & F. gigantica & N/A & H_21 \\
GU112459.1 & F. gigantica & N/A & H_21 \\
GU112470.1 & F. hepatica & N/A & H_4 \\
GU112469.1 & F. hepatica & N/A & H_4 \\
GU112472.1 & China & F. gigantica & N/A & H_21 \\
GU112473.1 & F. gigantica & N/A & H_21 \\
GU112484.1 & F. gigantica & N/A & H_21 \\
GU112485.1 & F. gigantica & N/A & H_21 \\
GU112487.1 & Intermediate & N/A & H_21 \\
GU112488.1 & Intermediate & N/A & H_21 \\
GU112489.1 & Intermediate & N/A & H_21 \\
GU112490.1 & Intermediate & N/A & H_21 \\
AF215860.1 & Outgroup & Schistosoma_japonicum & N/A & H_22 \\
\hline
\end{tabular}

samples, which were isolated to haplotypes H_12 and H_13 as part of the haplogroup. Haplotype H_8 and H_9 were common among the localities within the scope of this study, that is, KZN and MP, while haplotypes H_2, H_3, H_7 and H_10 were unique to KZN. Haplotypes H_1 and H_5 were shared between KZN and Highveld (MP), and haplotype H_11 contained sequences from the highveld and lowveld (Belfast) of MP. Haplotypes H_15 and H_20 contained sequences from the highveld of MP, while haplotype H_14 was isolated to the Belfast locality and haplotype H_6 was isolated to Zimbabwean isolates.

Principal coordinate analysis supports the genetic distance and distribution of haplotypes, with the clustering of individuals being similar to the respective $F$. gigantica and F. hepatica haplogroups, as well as the outgroup. The PCoA plot also shows $11.38 \%$ of the variation being attributed to the left axis and 55.52\% to the bottom axis (Figure 5).

\section{Discussion}

Phenotypic identification of Fasciola isolates is routinely used although with difficulties (Ai et al. 2011). Molecular techniques in the differentiation of Fasciola isolates have been found to be effective in disease control and management (Ai et al. 2011; Beesley et al. 2017; Itagaki et al. 1998; Mucheka et al. 2015). In our study, we were able to differentiate $F$. hepatica and F. gigantica isolates using phylogenetic analysis of the partial COI region, which showed distinct clades of the two species. Fasciola hepatica isolates were restricted to KZN and the highveld area of the MP province and $76.5 \%$ to the lowveld area in Belfast. The F. gigantica isolates were restricted to the lowveld (Belfast) region of MP, with a 23.5\% prevalence over $F$. hepatica in the same locality. This study has shown similar results, with respect to the distribution of $F$. hepatica and F. gigantica in the KZN and MP provinces of South Africa, to those recorded by Mucheka et al. (2015). The consistency in the results of this study with those observed in cited studies suggests the validity of the distribution patterns of Fasciola spp. in the study areas of South Africa.

A major driving factor of the wide distribution of $F$. gigantica and F. hepatica is the dependence of the life cycle on the fresh 


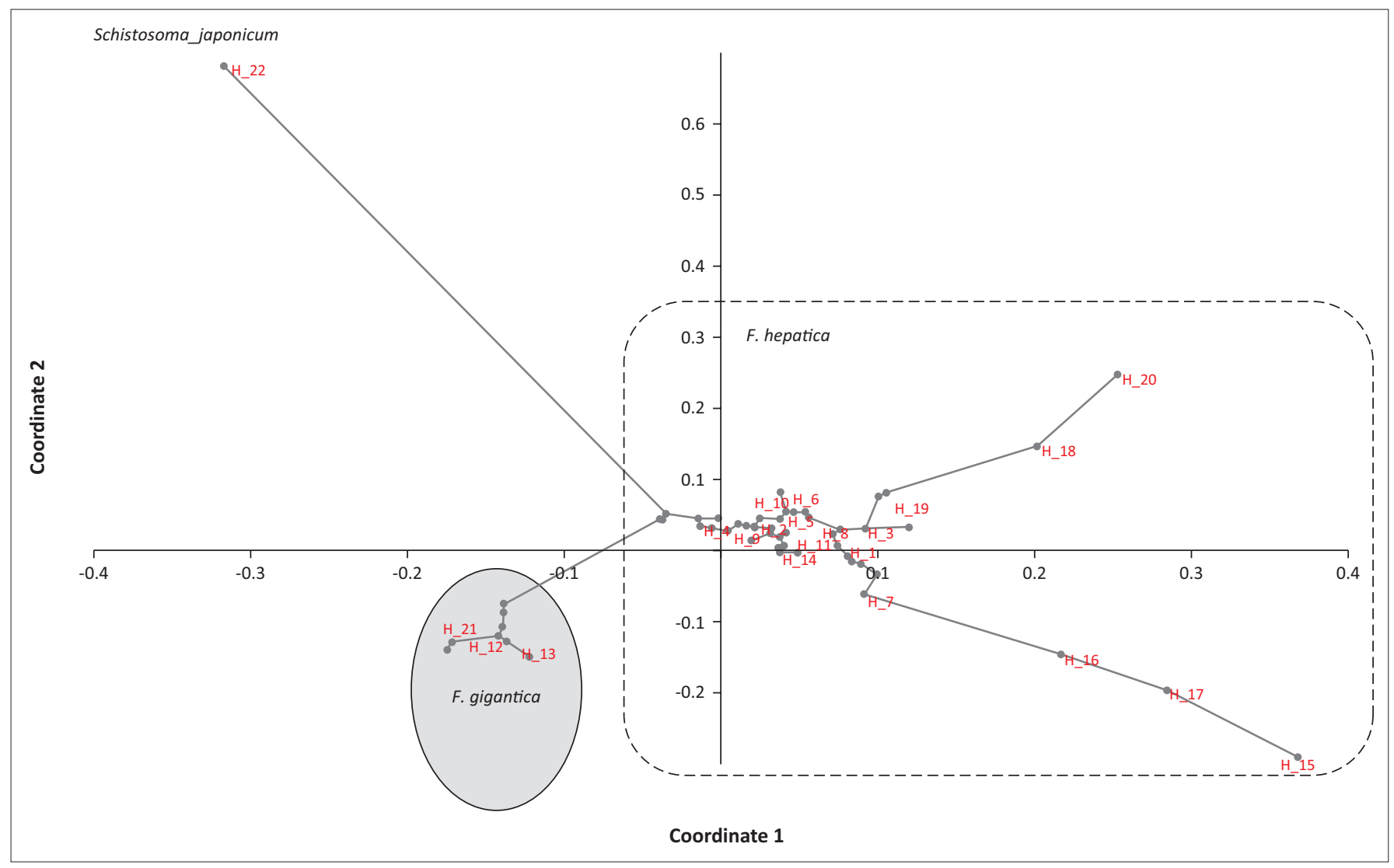

FIGURE 4: Principal coordinates analysis of Fasciola spp. based on the COI mitochondrial marker. Haplotypes associated with the individuals of the metapopulations of this study are indicated in red.

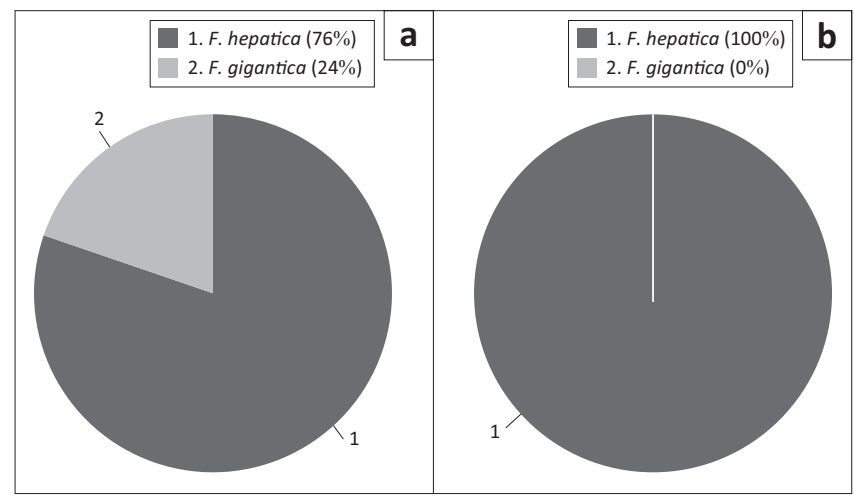

FIGURE 5: Prevalence of the Fasciola spp. isolated from the KwaZulu-Natal and Mpumalanga provinces of South Africa. (a) PaardePlaas, Belfaxt (Mpumalanga), (b) KwaZulu-Natal and Mpumalanga Highveld. The dark grey colour represents F. hepatica while the light grey colour represents F. gigantica.

water snail intermediate host (Bargues et al. 2001; Marquardt \& Demaree 1985; Mas-Coma et al. 2009). Although several snail species are used as intermediate hosts by fasciolids, Lymnaea spp. are notably the primary intermediate host of Fasciola spp. in South Africa. Lymnaea (Galba) truncatula is the preferred intermediate host of F. hepatica in Europe, and studies in South Africa have reported its distribution across the KZN and MP regions, as well as in the south of the Western Cape province (De Kock et al. 2003). Lymnaea (Pseudosuccinea) columella is known to be more invasive and widely distributed in South Africa and is an intermediate host for both F. hepatica and F. gigantica. Results of this study show similarities in the geographical distribution of the Lymnaeid species (De Kock et al. 2003) transmitting the two Fasciola species. Lymnaea natalensis has been identified as an intermediate host for F. gigantica (De Kock et al. 1989); hence, its distribution in South Africa can be related to that of F. gigantica. It has been reported to be present in the MP province of South Africa (De Kock et al. 1989), which could explain the presence of F. gigantica isolates in the Belfast region apart from the presence of L. columella.

The distribution of the snail intermediate hosts and the Fasciola spp. is dependent on several environmental factors, which, to a certain extent, are specific to the snail species. Lymnaea truncatula shows preference to the cooler areas and is most abundant in relatively high altitudes (De Kock et al. 2003), while L. natalensis shows a wide distribution in lower altitudes. Lymnaea columella shares a similar distribution with L. truncatula and has been shown to be highly invasive and adaptive as well. The present study showed high prevalence of F. hepatica in KwaZulu-Natal and the Highveld and Belfast of the MP province. Previous studies have shown similar results (Mucheka et al. 2015), giving an inclination to attributing the spread of F. hepatica in South Africa (within the study scope) to preferred habitats of the intermediate host snails L. trancatula and L. columella. Fasciola gigantica isolates were only found in the Belfast region of the MP province, which could be because of the area being suitable for breeding of L. natalensis and L. columella. The presence of both Fasciola spp. was noted in the Belfast region with two cattle infected with both and further studies should be conducted 
to determine the existence of intermediate forms of Fasciola, as they have been reported in regions showing species overlap, such as China (Ai et al. 2011). No intermediates were identified in the current study; however, the F. gigantica isolates from Belfast showed a close relationship with intermediates from China.

A link between environmental conditions and genetic diversity has been established based on Darwin's theory of adaptation to environmental stresses as well as geographical location (Walker et al. 2011). The results of this study demonstrate low interspecific genetic diversity ( $\pi$ range between metapopulations $=0.06901-0.10911$ and 0.07784 overall) between the flukes. This was comparatively higher than that observed by Ai et al. (2011) in a study of diversity of flukes; however, their study consisted of isolates with a wider geographical distribution. Elliott et al. (2014) recorded lower diversity in F. hepatica isolates from Australia. The low nucleotide diversity suggests a recent population bottleneck or founder effects as the flukes are not indigenous to South Africa but have rather spread from Eurasia (Mas-Coma et al. 2009). A relatively high haplotype diversity $(h d=0.8957)$ was also observed in this study, which is comparatively similar to that noted by Mucheka et al. (2015) in a study of Fasciola isolates from South Africa and Zimbabwe. Notably, only one F. hepatica haplotype was shared between the study isolates and GenBank-derived isolates from South Africa (KZN), Niger and China. The shared haplotype suggests a phylogenetic relationship between the isolates.

Propagated by the highly invasive $L$. columella and L. truncatula intermediate host snails, F. hepatica shows an expanding distribution globally (Mas-Coma, Esteban \& Bargues 1999). Lymnaea columella was first reported in South Africa in 1942, with studies showing rapid expansion of its distribution across sub-Saharan Africa (Appleton 2003). Fasciola gigantica has been reported to be not as widely distributed as F. hepatica in South Africa, however (De Kock et al. 1989; Mucheka et al. 2015) unlike countries in Africa, such as Zimbabwe where it is predominant (Mucheka et al. 2015). Fasciola gigantica isolates from this study did not share any haplotypes with the F. gigantica GenBank isolates; however, they showed a relationship with only one mutational step between the haplotypes, which suggests a distant relation between the isolates. The isolates forming part of the F. gigantica haplogroup could share a distant maternal lineage with geographical isolation as well as microevolution contributing to diversity. Fasciola gigantica is reported to have spread to Africa earlier than F. hepatica (Mas-Coma et al. 2009) which could influence the rate of divergence of the populations isolated in South Africa because of the reported short time of haplotype change in fasciolids (Walker et al. 2011). The high haplotype diversity is also indicative of a recent population expansion, which can be attributed to the ability of fasciolids to adapt to a wide range of environmental conditions (Mas-Coma 2004; Mas-Coma et al. 2005). Climate change and human activities have been cited as major contributing factors of the transmission and spread of fascioliasis (Afshan et al. 2014;
Mas-Coma et al. 2009). Life cycles of both the liver flukes and their intermediate host snails are highly dependent on geo-climatic parameters, with emphasis on temperature, rainfall and altitude (Mas-Coma 2004). Variations in climatic conditions can result in the variations in genetic diversity of the liver fluke between populations, displaying spatial and temporal separation (Walker et al. 2011). Studies have shown that husbandry and management of farms influence the movement of the definitive hosts, which, in turn, affects the population genetic diversity of the parasites (Beesley et al. 2017; Mas-Coma et al. 2005; Semyenova et al. 2006). Currently, the authors could not find conclusive studies on patterns of movement of cattle and other livestock in South Africa.

\section{Conclusion}

Although an increase in the importance of facioliasis as a zoonotic disease has been observed, the paucity of information in Southern Africa on the phylogenetic relationships as well as genetic diversity of Fasciola spp. is evident. This study has demonstrated the presence of F. hepatica in both the KZN and MP provinces of South Africa, confirming a recent observation by Mucheka et al. (2015) with F. gigantica only observed in the lowveld of the MP province. Fasciola hepatica was shown to be prevalent in the two provinces studied and shows similarity to studies by Mucheka et al. (2015). A link between the distribution of Fasciola spp. and that of the Lymnaeid intermediate host snails has been established in the literature (Mas-Coma et al. 2009; Mucheka et al. 2015), giving an inclination to attributing the fasciolid distribution to that of the snail intermediate hosts. The mitochondrial COI marker showed high genetic diversity between the study populations; however, further studies using more variable and neutral markers, such as microsatellites, are required to elucidate population genetic structuring. Future research should be focused on elucidating the phylogeography of Fasciola spp. in other provinces of South Africa, as well as the parasiteintermediate host snail interactions. This study has added to the current knowledge regarding the distribution of Fasciola spp. in the KZN and MP provinces of South Africa. The study was however limited by sample size and the geographical distribution of sampling sites, which could both be increased to further elucidate the genetic structuring and distribution of Fasciola on a wider scope.

\section{Acknowledgements}

The authors would like to acknowledge the abattoirs in the KwaZulu-Natal and Mpumalanga provinces for kindly allowing them to sample on their properties. They also acknowledge the veterinarians who professionally isolated the Fasciola spp. from the slaughtered cattle. Finally, the authors acknowledge the College of Agriculture, Engineering and Science as well as the School of Life Sciences for hosting this research.

\section{Competing interests}

The authors declare that they have no financial or personal relationships that may have inappropriately influenced them in writing this article. 


\section{Authors' contributions}

T.J.C. was responsible for the greater part of the laboratory work, data analysis as well as writing of the manuscript. O.T.Z. supervised all aspects of this research, assisted with the laboratory work, data analysis, writing and revising the manuscript. S.M. conceived the idea, funded the research, facilitated and coordinated sample collection, supervised the research and writing of the manuscript.

\section{Funding information}

The National Research Foundation (NRF) of South Africa provided the scarce skills bursary to T.J.C. for conducting this study.

\section{Data availability statement}

Additional data not included in this manuscript will be made available on request.

\section{Disclaimer}

The views and opinions expressed in this article are those of the author(s) and do not necessarily reflect the official policy or position of any affiliated agency of the authors.

\section{References}

Afshan, K., Fortes-Lima, C.A., Artigas, P., Valero, M.A., Qayyum, M. \& Mas-Coma, S., 2014, 'Impact of climate change and man-made irrigation systems on the transmission risk, long-term trend and seasonality of human and animal fascioliasis in Pakistan', Geospatial Health 8(2), 317-334. https://doi.org/10.4081/gh.2014.22

Agatsuma, T., Arakawa, Y., Iwagami, M., Honzako, Y., Cahyaningsih, U., Kang, S.Y. et al. 2000, 'Molecular evidence of natural hybridization between Fasciola hepatica and F. gigantic', Parasitology International 49(3), 231-238. https://doi.org/10.1016/ S1383-5769(00)00051-9

Ai, L., Chen, M.X., Alasaad, S., Elsheikha, H.M., Li, J., Li, H.L. et al., 2011, 'Genetic characterization, species differentiation and detection of Fasciola spp. by molecular
approaches', Parasites \& Vectors 4(1), 101. https://doi.org/10.1186/1756-3305approache

Andrews, S., 1999, 'The life cycle of Fasciola hepatica', in J.P. Dalton (ed.), Fasciolosis, pp. 1-29, CABI Publishing, Oxfordshire, United Kingdom.

Appleton, C.C., 2003, 'Alien and invasive fresh water Gastropoda in South Africa', African Journal of Aquatic Science 28(1), 69-81. https://doi.org/10.2989/160859 14.2003.9626602

Ashrafi, K., 2015, 'The status of human and animal fascioliasis in Iran: A narrative review article', Iranian Journal of Parasitology 10(3), 306.

Bandelt, H.J., Forster, P. \& Röhl, A., 1999, 'Median-joining networks for inferring intraspecific phylogenies', Molecular Biology and Evolution 16(1), 37-48. https:// doi.org/10.1093/oxfordjournals.molbev.a026036

Bargues, M.D., Vigo, M., Horak, P., Dvorak, J., Patzner, R.A., Pointier, J.P. et al., 2001 'European Lymnaeidae (Mollusca: Gastropoda), intermediate hosts of trematodiases, based on nuclear ribosomal DNA ITS-2 sequences', Infection, Genetics and Evolution 1(2), 85-107. https://doi.org/10.1016/S1567-1348(01)00019-3

Beesley, N.J., Williams, D.J., Paterson, S. \& Hodgkinson, J., 2017, 'Fasciola hepatica demonstrates high levels of genetic diversity, a lack of population structure and high gene flow: Possible implications for drug resistance', International Journal for Parasitology 47(1), 11-20. https://doi.org/10.1016/j.ijpara.2016.09.007

Bernardo, C.D.C., Carneiro, M.B., Avelar, B.R.D., Donatele, D.M., Martins, I.V.F. \& Pereira, M.J.S., 2011, 'Prevalence of liver condemnation due to bovine fasciolosis in Southern Espírito Santo: Temporal distribution and economic losses', Revisto Brasileira de Parasitologia Veterinária 20(1), 49-53. https://doi.org/10.1590/ S1984-29612011000100010

Brennan, G.P., Fairweather, I., Trudgett, A., Hoey, E., McConville, M., Meaney, M. et al., 2007, 'Understanding triclabendazole resistance', Experimental and Molecula Pathology 82(2), 104-109. https://doi.org/10.1016/j.yexmp.2007.01.009

Brockwell, Y.M., Elliott, T.P., Anderson, G.R., Stanton, R., Spithill, T.W. \& Sangster, N.C., 2014, 'Confirmation of Fasciola hepatica resistant to triclabendazole in naturally infected Australian beef and dairy cattle', International Journal for Parasitology: Drugs and Drug Resistance 4(1), 48-54. https://doi.org/10.1016/j ijpddr.2013.11.005

Climate: Belfast, 2017a, 'Climate-data. 17/08.2017', viewed 03 March 2019, from https://en.climate-data.org/location/25742/.
Climate: Underberg, 2017b, 'Climate-data. 17/08.2017', viewed 03 March 2019, from https://en.climate-data.org/location/26845/.

Cuomo, M.J., Noel, L.B. \& White, D.B., 2009, Diagnosing medical parasites: A public health officers guide to assisting laboratory and medical officers, Air Education and Training Command Randolph AFB TX, viewed 05 September 2018, from http://www.dtic.mil/dtic/tr/fulltext/u2/a596737.pdf.

Cwiklinski, K., Allen, K., LaCourse, J., Williams, D.J., Paterson, S. \& Hodgkinson, J.E., 2015, 'Characterisation of a novel panel of polymorphic microsatellite loci for the liver fluke, Fasciola hepatica, using a next generation sequencing approach', Infection, Genetics and Evolution 32, 298-304. https://doi.org/10.1016/j.meegid. 2015.03.014

De Kock, K.K., Joubert, P.H. \& Pretorius, S.J., 1989, 'Geographical distribution and habitat preferences of the invader freshwater snail species Lymnaea columella (Mollusca: Gastropoda) in South Africa', The Onderstepoort Journal of Veterinary Research 56(4), 271-275.

De Kock, K.N., Wolmarans, C.T. \& Bornman, M., 2003, 'Distribution and habitats of the snail Lymnaea truncatula, intermediate host of the liver fluke Fasciola hepatica, in South Africa', Journal of the South African Veterinary Association 74(4), 117-122. https://doi.org/10.4102/jsava.v74i4.523

Elliott, T., Muller, A., Brockwell, Y., Murphy, N., Grillo, V., Toet, H.M. et al., 2014 'Evidence for high genetic diversity of NAD1 and COX1 mitochondrial haplotype among triclabendazole resistant and susceptible populations and field isolates of Fasciola hepatica (liver fluke) in Australia', Veterinary Parasitology 200(1), 90-96. https://doi.org/10.1016/j.vetpar.2013.11.019

Fairweather, I., 2009, 'Triclabendazole progress report, 2005-2009: An advancement of learning?', Journal of Helminthology 83(2), 139-150. https://doi.org/10.1017/ S0022149X09321173

Graczyk, T.K. \& Fried, B., 1999, 'Development of Fasciola hepatica in the intermediate host', in J.P. Dalton (ed.), Fasciolosis, pp. 31-46, CAB International Publishing, Wallingford, United Kingdom.

Hall, T., 2013, Biological sequence alignment editor software, Ibis Biosciences, Carlsbad, CA.

Hammer, Ø., Harper, D.A.T. \& Ryan, P.D., 2001, 'PAST: Paleontological statistics software package for education and data analysis', Palaeontologia Electronica 4(1), 1-9, viewed from http://palaeo-electronica.org/2001_1/past/issue1_01.htm.

Hashimoto, K., Watanobe, T., Liu, C.X., Init, I., Blair, D., Ohnishi, S. \& Agatsuma, T. 1997, 'Mitochondrial DNA and nuclear DNA indicate that the Japanese Fasciola species is F. gigantica', Parasitology Research 83(3), 220-225. https://doi.org/ $10.1007 /$ s004360050237

Itagaki, T. \& Tsutsumi, K.I., 1998, 'Triploid form of Fasciola in Japan: Genetic relationships between Fasciola hepatica and Fasciola gigantica determined by ITS-2 sequence of nuclear rDNA', International Journal for Parasitology 28(5), 777-781. https://doi. nuclear rDNA', International Journal for
org/10.1016/S0020-7519(98)00037-X

Itagaki, T., Tsutsumi, K.I., Ito, K. \& Tsutsumi, Y., 1998, 'Taxonomic status of the Japanese triploid forms of Fasciola: Comparison of mitochondrial ND1 and COI sequences with F. hepatica and F. gigantica', The Journal of Parasitology 84(2), 445-448.

Jamuar, S.S., D'Gama, A.M. \& Walsh, C.A., 2016, 'Somatic mosaicism and neurological diseases', in T. Lehner, B. Miller \& M. State (eds.), Genomics, circuits, and pathways in clinical neuropsychiatry, pp. 179-199, San Diego: Academic Press.

Keiser, J. \& Utzinger, J., 2007, 'Food-borne trematodiasis: Current chemotherapy and advances with artemisinins and synthetic trioxolanes', TRENDS in Parasitology 23(11), 555-562. https://doi.org/10.1016/j.pt.2007.07.012

Kelley, J.M., Elliott, T.P., Beddoe, T., Anderson, G., Skuce, P. \& Spithill, T.W., 2016 'Current threat of triclabendazole resistance in Fasciola hepatica', Trends in Parasitology 32(6), 458-469. https://doi.org/10.1016/j.pt.2016.03.002

Librado, P. \& Rozas, J., 2009, 'DnaSP v5: A software for comprehensive analysis of DNA polymorphism data', Bioinformatics 25(11), 1451-1452. https://doi.org/10.1093/ bioinformatics/btp187

Marquardt, W. \& Demaree, R., Jr., 1985, Parasitology, pp. 246-254, Macmillan Publishing Company, New York.

Mas-Coma, S., 2004, 'Human fascioliasis: Epidemiological patterns in human endemic areas of South America, Africa and Asia', Southeast Asian Journal of Tropical Medicine and Public Health 35(Suppl 1), 1-11.

Mas-Coma, S., 2005, 'Epidemiology of fascioliasis in human endemic areas', Journal of Helminthology 79(3), 207-216. https://doi.org/10.1079/JOH2005296

Mas-Coma, S. \& Bargues, M., 1997, 'Human liver flukes: A review', Research Reviews Parasitology 57, 145-218.

Mas-Coma, S., Bargues, M.D. \& Valero, M.A., 2005, 'Fascioliasis and other plantborne trematode zoonoses', International Journal for Parasitology 35(11-12) 1255-1278. https://doi.org/10.1016/j.ijpara.2005.07.010

Mas-Coma, S., Esteban, J.G. \& Bargues, M.D., 1999, 'Epidemiology of human fascioliasis: A review and proposed new classification', Bulletin of the World Health Organization 77(4), 340.

Mas-Coma, S., Valero, M.A. \& Bargues, M.D., 2009a, 'Climate change effects on trematodiases, with emphasis on zoonotic fascioliasis and schistosomiasis', Veterinary Parasitology 163(4), 264-280. https://doi.org/10.1016/j.vetpar.2009. 03.024

Mas-Coma, S., Valero, M.A. \& Bargues, M.D., 2009b, 'Fasciola, lymnaeids and human fascioliasis, with a global overview on disease transmission, epidemiology, evolutionary genetics, molecular epidemiology and control', Advances in Parasitology 69, 41-146. https://doi.org/10.1016/S0065-308X(09)69002-3

McKiernan, H.E. \& Danielson, P.B., 2017, 'Molecular diagnostic applications in forensic science', in G. Patrinos, W. Ansorge \& P.B. Danielson (eds.), Molecular diagnostics, 3rd edn., pp. 371-394, Amsterdam, Academic Press. 
Mucheka, V.T., Lamb, J.M., Pfukenyi, D.M. \& Mukaratirwa, S., 2015, 'DNA sequence analyses reveal co-occurrence of novel haplotypes of Fasciola gigantica with $F$. hepatica in South Africa and Zimbabwe', Veterinary Parasitology 214(1-2), pp. hepatica in South Africa and Zimbabwe', Veterinary Para

Nguyen, T.G.T., Van De, N., Vercruysse, J., Dorny, P. \& Le, T.H., 2009, ‘Genotypic characterization and species identification of Fasciola spp. with implications regarding the isolates infecting goats in Vietnam', Experimental Parasitology 123(4), 354-361. https://doi.org/10.1016/j.exppara.2009.09.001

Patwardhan, A., Ray, S. \& Roy, A., 2014, 'Molecular markers in phylogenetic studies - A review', Journal of Phylogenetics \& Evolutionary Biology 2(2), 131.

Peng, M., Ichinomiya, M., Ohtori, M., Ichikawa, M., Shibahara, T. \& Itagaki, T., 2009, 'Molecular characterization of Fasciola hepatica, Fasciola gigantica, and aspermic Fasciola sp. in China based on nuclear and mitochondrial DNA', Parasitology Research 105(3), 809. https://doi.org/10.1007/s00436-009-1459-0

Periago, M.V., Valero, M.A., El Sayed, M., Ashrafi, K., El Wakeel, A., Mohamed, M.Y. et al., 2008, 'First phenotypic description of Fasciola hepatica/Fasciola gigantic intermediate forms from the human endemic area of the Nile Delta, Egypt', Infection Genetics and Evolution 8(1), 51-58. https://doi.org/10.1016/j.meegid.2007.10.001

Robles-Pérez, D., García-García, P., Martínez-Pérez, J.M., Rojo-Vázquez, F.A. \& Martínez-Valladares, M., 2015, 'Analysis of genetic variability of Fasciola hepatica populations from different geographical locations by ISSR-PCR', Parasitology 142(4), 527-533. https://doi.org/10.1017/S003118201400153X

Ronquist, F. \& Huelsenbeck, J.P., 2003, 'MRBAYES 3: Bayesian phylogenetic inference under mixed models', Bioinformatics 19, 1572-1574. https://doi.org/10.1093/ bioinformatics/btg180

Schweizer, G., Meli, M.L., Torgerson, P.R., Lutz, H., Deplazes, P. \& Braun, U., 2007 'Prevalence of Fasciola hepatica in the intermediate host Lymnaea truncatula detected by real time TaqMan PCR in populations from 70 Swiss farms with cattle husbandry', Veterinary Parasitology 150, 164-169. https://doi.org/10.1016/j. vetpar.2007.08.006
Semyenova, S.K., Morozova, E.V., Chrisanfova, G.G., Gorokhov, V.V., Arkhipov, I.A., Moskvin, A.S. et al., 2006, 'Genetic differentiation in eastern European and western Asian populations of the liver fluke, Fasciola hepatica, as revealed by mitochondrial nad1 and cox1 genes', Journal of Parasitology 92(3), 525-530. https://doi.org/10.1645/GE-673R.1

Spithill, T.W. \& Dalton, J.P., 1998, 'Progress in development of liver fluke vaccines', Parasitology Today 14(6), 224-228. https://doi.org/10.1016/S0169-4758(98) 01245-9

Thanh, N.T., 2012, 'Zoonotic fasciolosis in Vietnam: Molecular identification and geographical distribution', Doctoral dissertation, Tesis de Doctorado, Ghent University, Bélgica.

Vilas, R., Vázquez-Prieto, S. \& Paniagua, E., 2012, 'Contrasting patterns of population genetic structure of Fasciola hepatica from cattle and sheep: Implications for the evolution of anthelmintic resistance', Infection, Genetics and Evolution 12(1), 45-52. https://doi.org/10.1016/j.meegid.2011.10.010

Walker, S.M., Johnston, C., Hoey, E.M., Fairweather, I., Borgsteede, F., Gaasenbeek, C. et al., 2011, 'Population dynamics of the liver fluke, Fasciola hepatica: The effect of time and spatial separation on the genetic diversity of fluke populations in the Netherlands', Parasitology 138(2), 215-223. https://doi.org/10.1017/S003 1182010001149

Walker, S.M., Makundi, A.E., Namuba, F.V., Kassuku, A.A., Keyyu, J., Hoey, E.M. et al., 2008, 'The distribution of Fasciola hepatica and Fasciola gigantica within southern Tanzania-constraints associated with the intermediate host', Parasitology 135(4), 495-503. https://doi.org/10.1017/S0031182007004076

WHO, 1995, Control of foodborne trematode infections, Technical Report Series, pp. 849-861, World Health Organization, Geneva.

Winkelhagen, A.J., Mank, T., De Vries, P.J. \& Soetekouw, R., 2012, 'Apparent triclabendazole-resistant human Fasciola hepatica infection, the Netherlands', Emerging Infectious Diseases 18(6), 1028. https://doi.org/10.3201/eid1806. 120302 